\title{
CONTRIBUIÇÃO DE ATIVIDADE EXPERIMENTAL NA MUDANÇA CONCEITUAL DE ALUNOS SUPERDOTADOS
}

\author{
CONTRIBUTION OF EXPERIMENTAL ACTIVITY TO THE \\ CONCEPTUAL CHANGE OF THE GIFTED STUDENTS
}

DOI: http://dx.doi.org/10.5965/1984317816012020127 Felipe Rodrigues Martins
Instituto Superior de Educação do Rio de Janeiro
felipe_prof@yahoo.com

Cristina Maria Carvalho Delou Universidade Federal Fluminense cristinadelou@id.uff.br

Fernanda Serpa Cardoso Universidade Federal Fluminense fernandalabiomol@yahoo.com.br

\begin{abstract}
RESUMO
REFERENCIAL: O comportamento de superdotação reflete interação entre capacidade acima da média, elevados níveis de criatividade e comprometimento com a tarefa. $\mathrm{O}$ atendimento, como forma de suplementação, pode ser feito através de atividades experimentais que conduzam a desestabilização, a reflexão crítica, a curiosidade, entre outras. OBJETIVO: Avaliar uma atividade pedagógica envolvendo experimentos químicos como ferramenta de atendimento à alunos superdotados. MATERIAL E MÉTODOS: Pesquisa participante qualitativa, realizada com aplicação de questionários semiestruturados. Os sujeitos da pesquisa foram crianças e adolescentes, identificados como superdotados, atendidos pela Escola de Inclusão da Universidade Federal Fluminense, em atividade oferecida durante o IV Curso de Verão em 2016. As respostas dos pré-testes e pós-testes foram analisadas e categorizadas, pela comparação com gabarito predefinido. RESULTADOS E DISCUSSÃO: A transcrição de algumas respostas dos questionários ratifica a proposição de que a atividade experimental mediada pelo professor pode tanto promover a mudança conceitual como a apropriação de novos conceitos. Tal mudança corrobora para a desconstrução do mito de que o indivíduo superdotado não necessita de atendimento. CONCLUSÃO: Após a atividade, o percentual de participantes que demonstrou ter um conhecimento total sobre o assunto aumentou, bem como diminuiu o número de participantes que demonstrou ter conhecimento nulo.
\end{abstract}

Palavras-chave: Superdotação. Atendimento Educacional Especializado. Suplementação. Experimentação. Ensino de Química.

\section{ABSTRACT}

REFERENCES: The behavior of giftedness reflects the interaction between capacity above average, high levels of creativity and commitment to the task. The service, as form of supplementation, can be done through experimental activities that lead to destabilization, critical reflection, curiosity, among others. OBJECTIVE: To evaluate a pedagogical activity involving chemical experiments as a tool to assist gifted students. MATERIAL AND METHODS: Qualitative participant research, carried out with the application of semistructured questionnaires. The subjects of the research were children and adolescents, identified as gifted, attended by the Escola de Inclusão of the Universidade Federal Fluminense, in an activity offered during the IV Curso de Verão in 2016. Pre-test and posttest responses were analyzed and categorized, by comparison with predefined feedback. 
RESULTS AND DISCUSSION: The transcription of some answers of the questionnaires ratifies the proposition that the experimental activity mediated by the teacher can both promote conceptual change and the appropriation of new concepts. Such a change corroborates the deconstruction of the myth that the gifted individual does not need service. CONCLUSION: After the activity, the percentage of participants who demonstrated a complete knowledge about the subject increased, as well as decreased the number of participants who demonstrated to have no knowledge.

Keywords: Giftedness. Specialized Educational Services. Supplementation. Experimentation. Chemistry Teaching.

\section{SOBRE SUPERDOTAÇÃO}

Diante do desafio de universalizar o acesso à educação, na França, entre o final do século XIX e o início do século XX, Alfred Binet e Théodore Simon elaboraram uma ferramenta capaz de classificar e separar as crianças segundo suas possibilidades de aprendizagem (DELOU, 2001). Posteriormente, na década de 1910, tal ferramenta em forma de testes chegou aos Estados Unidos e foi adaptada por Lewis Terman e sua equipe da Universidade de Stanford, passando a ser denominada escala de Stanford-Binet.

Nela, predominava a visão psicométrica de inteligência segundo a qual os indivíduos com altas habilidades ou superdotação deveriam apresentar um resultado igual ou superior a 140 no teste de inteligência (OLIVEIRA, 2007). Entretanto, o uso excessivo dos testes psicométricos conheceu suas primeiras críticas já na década de 1930, em função do seu caráter discriminatório (DELOU, 2001).

A partir dos anos 1960, educadores e psicólogos tornaram-se ainda mais críticos quanto ao significado e importância dos testes de inteligência na descrição das habilidades e realização cognitiva em virtude dos problemas sociais gerados nas décadas anteriores. Para os críticos, os testes realizados tinham como base determinada cultura, o que colocava as minorias étnicas e sociais em considerável desvantagem em relação àquele tipo de avaliação, reforçando a desigualdade social existente (PATTO, 1997).

Esse mesmo período foi marcado pelo lançamento do satélite soviético Sputinik, o que foi definitivo no sentido de voltar o interesse de americanos e ingleses para uma educação de excelência. Os programas para atendimento de alunos com altas habilidades ou superdotação desenvolvidos em escolas públicas 
nesses países receberam grandes verbas, apesar das críticas, tanto do ponto de vista político quanto teórico, aos testes de inteligência utilizados na identificação do público-alvo (DELOU, 2001). Desde então, especialmente os Estados Unidos passaram a viver o dilema de conciliar dois valores educacionais fundamentais: a equidade e a excelência (SÃO PAULO, 2008).

Ao longo da década de 1980, emergiram duas teorias cognitivistas muito importantes para a concepção contemporânea de inteligência: a Teoria Triárquica da Inteligência de Sternberg (1987) e a Teoria das Inteligências Múltiplas de Gardner (1983). Nesse mesmo contexto, foram também desenvolvidas duas novas teorias sobre superdotação: o Modelo de Superdotação dos Três Anéis de Renzulli (1978, 1986) e o Modelo Multifatorial da Sobredotação de Mönks (1988).

Segundo o modelo dos Três Anéis de Renzulli, o comportamento de superdotação reflete uma interação entre três grupamentos básicos de traços humanos: capacidade acima da média, elevados níveis de comprometimento com a tarefa e elevados níveis de criatividade. Os indivíduos com tal comportamento são aqueles que possuem ou são capazes de desenvolver esse conjunto de traços e aplicá-los a qualquer área potencialmente valiosa do desempenho humano (RENZULLI e REIS, 1997, apud RENZULLI, 2004). Nem sempre estes componentes basilares aparecem simultaneamente ou na mesma proporção, além disso, o desenvolvimento destas características depende tanto do envolvimento da família, quanto da atenção da escola e colegas.

Renzulli (2004) apresenta dois tipos distintos de superdotados: aquele que apresenta a superdotação acadêmica, sendo mais valorizado pelo sistema educacional formal, uma vez que suas habilidades analíticas podem ser facilmente mensurada pelos testes padronizados, se mantendo relativamente estável ao longo da vida, e o indivíduo com superdotação produtivo-criativa, que está relacionada com o desenvolvimento de ideias, produtos, conhecimentos e expressões artísticas.

A compreensão da superdotação segundo este prisma permite tanto transcender a ideia reducionista de que um indivíduo possa ser classificado (ou não) como superdotado quanto impõe a responsabilidade de oferecer oportunidades para que estes indivíduos atinjam seu potencial de desempenho. Contudo, a identificação 
também carrega consigo o fantasma da rotulação. No caso da identificação do indivíduo com altas habilidades, a questão é ainda mais complexa: enquanto os sujeitos com deficiência, uma vez identificados, despertam nos outros o sentimento de desvantagem, os alunos superdotados são encarados de forma antagônica porque, segundo o senso comum, eles são privilegiados (RECH e FREITAS, 2005).

A Lei de Diretrizes e Bases da Educação Nacional (LDBEN), em seu Artigo $58^{\circ}$, indica que são público-alvo da Educação Especial os alunos com deficiência, transtornos globais do desenvolvimento e altas habilidades ou superdotação (BRASIL, 1996). Segundo a Política Nacional de Educação Especial na perspectiva da Educação Inclusiva, os alunos com deficiência são aqueles que têm impedimentos de longo prazo, de natureza física, mental, intelectual ou sensorial, que, em interação com diversas barreiras, podem ter restringida sua participação plena na escola e na sociedade. Os alunos com transtornos globais são aqueles que apresentam alterações qualitativas das interações sociais recíprocas e na comunicação, um repertório de interesses e atividades restrito, estereotipado e repetitivo. Alunos com altas habilidades ou superdotação demonstram potencial elevado em qualquer uma das seguintes áreas, isoladas ou combinadas: intelectual, acadêmica, liderança, psicomotricidade e artes; além de apresentarem elevada criatividade, grande envolvimento na aprendizagem e realização de tarefas em áreas de seu interesse (BRASIL, 2008). Estes alunos têm garantido o direito ao atendimento educacional especializado (AEE) transversal a todos os níveis, etapas e modalidades, preferencialmente na rede regular de ensino e, como todos os demais alunos, têm garantidos o acesso aos níveis mais elevados do ensino, da pesquisa e da criação artística, segundo suas capacidades.

Para os alunos superdotados, faz-se necessário, entre outras coisas, cumprir a legislação no que se refere: ao atendimento suplementar para aprofundar e/ou enriquecer o currículo; à aceleração/avanço, regulamentados pelos respectivos sistemas de ensino, permitindo, inclusive, a conclusão da Educação Básica em menor tempo; à inclusão do atendimento educacional ao superdotado nos projetos pedagógicos e regimentos escolares, inclusive por meio de convênios com instituições de ensino superior e outros segmentos da comunidade (BRASIL, 2001). 
Recomenda-se, inclusive, às escolas de Educação Básica a constituição de parcerias com Instituições de Ensino Superior (IES) para a identificação de alunos que apresentem altas habilidades ou superdotação, apoio ao prosseguimento de estudos na Educação Básica e ao desenvolvimento de estudos no Ensino Superior, inclusive mediante a oferta de bolsas de estudo, destinando-se tal apoio prioritariamente àqueles alunos que pertençam aos estratos sociais de baixa renda (BRASIL, 2001). A Resolução no 4, em seu Artigo $7^{\circ}$, propõe que os alunos com altas habilidades ou superdotação tenham suas atividades de enriquecimento curricular desenvolvidas no âmbito de escolas públicas de ensino regular em interface com as instituições de ensino superior e institutos voltados ao desenvolvimento e promoção da pesquisa, das artes e dos esportes (BRASIL, 2009).

Cumprindo o que foi determinado pela legislação, uma parceria entre a Universidade Federal Fluminense (UFF), o Instituto Vital Brazil (IVB) e escolas da Educação Básica, foi estabelecida através de uma Rede de Interações com o objetivo de atender alunos que apresentassem indicadores de altas ou superdotação. Dentre o atendimento na forma de suplementação, realizado pela Rede de Interações, nesse caso mais específico pela UFF, é ofertado desde 2013 o Curso de Férias para Alunos Superdotados(CARDOSO, 2016). Em 2016, ano em que a atividade experimental relatada no presente artigo foi realizada, o Curso de Férias ocorreu nos espaços do IVB.

\section{SOBRE A EXPERIMENTAÇÃO NO ENSINO DE QUÍMICA}

O conhecimento científico depende de uma abordagem experimental posto que a organização desse conhecimento ocorre nos entremeios na investigação. A experimentação ocupa um lugar privilegiado numa metodologia científica racionalista pautada tanto no processo indutivo, proposto por Bacon, quanto no processo dedutivo elaborado por Descartes. Neste aspecto, conforme afirma Giordan, "cumpre destacar a característica de controle que a experimentação passa a exercer com a transformação do pensamento científico" (GIORDAN, 1999, p. 45).

O discurso de Giordan é pautado na dimensão psicológica e sociológica da experimentação sugerida por Bachelard (1996). Segundo este, o erro teria papel 
destacado no progresso da ciência. Propondo que a experiência exigente é aquela na qual ocorre o erro, Bachelard aponta a desestabilização, a quebra de previsibilidade e a reflexão crítica como fomentadores do comprometimento do aluno com sua aprendizagem.

O experimento exigente desenvolve um processo de representação da realidade através de discursos mentais e sociais. O erro promove o diálogo e a reelaboração do modelo representativo da realidade. O professor ocupa um lugar estratégico na direção do que é cientificamente aceito (BACHELARD, 1996). A experimentação deve alimentar o processo de significação do mundo quando se permite operá-la no plano da simulação da realidade (GIORDAN, 1999).

Nesse caso, a experimentação assume o papel de mediação da realidade simulada como etapa intermediária entre o fenômeno e a representação que o sujeito lhe confere (op. cit.). Contudo, a experimentação simulada não se sobrepõe à experimentação fenomenológica, mas permite o cultivo da imaginação do sujeito, portanto a simulação deve ser incorporada às práticas educacionais como estratégia pedagógica (BACHELARD, 1996).

A atividade experimental também pode ser observada à luz pedagogia problematizadora em oposição à educação bancária (FREIRE 2005). De acordo com esta pedagogia, o professor deve suscitar nos estudantes o espírito crítico, a curiosidade, a não aceitação do conhecimento simplesmente transferido.

Se há uma prática exemplar como negação da experiência formadora é a que dificulta ou inibe a curiosidade do educando e, em consequência, a do educador. (...) Nenhuma curiosidade se sustenta eticamente no exercício da negação da outra curiosidade. (...) Estimular a pergunta, a reflexão crítica sobre a própria pergunta, o que se pretende com esta ou com aquela pergunta em lugar da passividade em face das explicações discursivas do professor, espécies de resposta a perguntas que não foram feitas. Isto não significa realmente que devamos reduzir a atividade docente em nome da defesa da curiosidade necessária, a puro vai-e-vem de perguntas e respostas, que burocraticamente se esterilizam. A dialogicidade não nega a validade de momentos explicativos, narrativos em que o professor expõe ou fala do objeto. $O$ fundamental é que professor e alunos saibam que a postura deles, do professor e dos alunos, é dialógica, aberta, curiosa, indagadora e não apassivada, enquanto fala ou enquanto ouve. O que importa é que professor e alunos se assumam epistemologicamente curiosos (FREIRE, 2006, p. 33). 
Por outro lado, pode-se ainda construir atividades experimentais envolvendo fenômenos químicos e/ou físicos que estimulem $\mathrm{o}$ interesse dos alunos e o engajamento em atividades subsequentes (FRANCISCO JR, 2008). A atividade experimental constitui um dos aspectos-chave do processo de ensino-aprendizagem de ciências e experimentos podem potencializar o envolvimento dos alunos acarretando evoluções em termos conceituais (FRANCISCO JR. et al, 2008).

Trabalhando à luz da Experimentação Problematizadora, Delizoicov (2005) propõe em suas pesquisas a "problematização" como eixo estruturador de atividades a serem realizadas com alunos, indicando que o processo de construção ou aprimoramento de algum conhecimento deve ser realizado através da apresentação de situações reais que os alunos conhecem e que possam presenciar, e que estão envolvidas no tema a ser discutido pelo grupo. É o momento da função coordenadora do professor auxiliando aos alunos a apreenderem e compreenderem a situação ao qual estão sendo apresentados, culminando no momento em que o próprio aluno sinta necessidade de adquirir novos conhecimentos para seguir na interpretação dos fatos.

O passo seguinte, para Delizoicov (2005) é quando o aluno seleciona, isoladamente ou em grupo, novos conceitos que podem auxiliar sua compreensão, de forma a retornar ao problema ou mesmo aplicar os conhecimentos adquiridos em outras situações problemas que possam ser apresentadas ou levantadas por eles mesmos.

\section{OBJETIVO}

Analisar uma atividade pedagógica envolvendo experimentos químicos, em atendimento à legislação no que tange às atividades suplementares em interface com as instituições de ensino superior e institutos voltados ao desenvolvimento e promoção da pesquisa como forma de atendimento à demanda de alunos com comportamento de superdotação. 


\section{MATERIAL E MÉTODOS}

A pesquisa desenvolvida foi desenhada e realizada através um estudo do tipo descritivo-analítico com abordagem qualitativa (CONDURÚ E PEREIRA, 2010). Para a obtenção dos resultados foi realizada pesquisa participante e aplicação de questionários semiestruturados (GIL, 2008).

Os sujeitos da pesquisa foram crianças e adolescentes matriculados regularmente em escolas públicas ou privadas do município de Niterói ou de municípios vizinhos e identificados com altas habilidades ou superdotação atendidos pela Escola de Inclusão da Universidade Federal Fluminense. A pesquisa foi pautada na eticidade, o que implica em consentimento livre e esclarecido dos indivíduos-alvo e a proteção a grupos vulneráveis e aos legalmente incapazes; ponderação entre riscos e benefícios, tanto atuais como potenciais, individuais ou coletivos, comprometendo-se com o máximo de benefícios e o mínimo de danos e riscos; garantia de que danos previsíveis serão evitados; relevância social da pesquisa o que garante a igual consideração dos interesses envolvidos, não perdendo o sentido de sua destinação sócio-humanitária (BRASIL, 2016).

A atividade foi oferecida durante o IV Curso de Verão para crianças e adolescentes superdotados atendidos pela Escola de Inclusão da Universidade Federal Fluminense realizado no Instituto Vital Brazil no ano de 2016. Neste encontro os sujeitos foram divididos aleatoriamente em grupos não respeitando escolarização ou faixa etária. $\mathrm{Na}$ atividade, os participantes responderam a um préteste e um pós-teste a fim de avaliar tanto seus conhecimentos prévios sobre cada tema quanto o que foi aprendido ao final de cada experimento.

Além dos testes, foi também elaborado um questionário fechado a ser preenchido pelos pais / responsáveis com o objetivo de caracterizar a criança ou adolescente superdotado. Neste questionário, foram solicitadas as seguintes informações: idade, série, tipo de escola, tipo de teste realizado para a identificação da superdotação; histórico de reprovação e/ou aceleração; interesse pelas Ciências da Natureza e participação prévia em atividades afins.

O pré-teste e o pós-teste foram constituídos de três questões: 1. Por que a vela apaga quando a colocamos dentro de um recipiente fechado?; 2. Qual(is) 
produto(s) de uma reação de combustão?; 3. Você sabe informar um tipo de combustão cujos produtos não geram impactos ambientais?. A elaboração das questões teve como objetivo verificar a mudança de perfil conceitual sobre reações de combustão e poluição (MORTIMER, 1992).

Inicialmente, o professor, no papel de mediador, conversou com os sujeitos da pesquisa a respeito do fenômeno da combustão. Eles tiveram a oportunidade de expor seus conhecimentos prévios sobre o tema bem como conversaram sobre possíveis materiais combustíveis. A conversa levou-os aos elementos essenciais para a ocorrência de uma reação de combustão: combustível, oxigênio e ignição. Desta forma, o professor provocou-os realizando um experimento bastante simples, porém incansavelmente discutido entre professores e pesquisadores na área de ensino de Química: a queima de uma vela dentro de um recipiente fechado (BRAATHEN, 2000).

Este primeiro experimento foi realizado com o objetivo de ratificar a necessidade do oxigênio como forma de manutenção da chama. Contudo, na sequência, foi realizado um experimento distinto: foram acesas três velas de tamanhos diferentes e o recipiente fechado foi também colocado sobre elas a fim de se observar o instante em que cada vela apagava.

Este experimento foi realizado com o objetivo de fazer os sujeitos refletirem sobre o conhecimento (re)construído. Considerando a hipótese de que a chama de uma vela apaga em um recipiente fechado pela falta de oxigênio, a expectativa por parte dos sujeitos era de que as três velas apagassem ao mesmo tempo no segundo experimento. Contudo, um resultado diferente permitiria uma nova discussão acerca das condições necessárias para a ocorrência da reação tais como, por exemplo, o contato entre os reagentes.

O assunto em questão, no entanto, não ficou limitado à queima de material orgânico, mas estendeu-se especialmente à combustão do hidrogênio. A atenção deve-se às recentes pesquisas que sinalizam para importância do hidrogênio como combustível não-poluente, entretanto, não deixou-se de enfatizar os riscos de um combustível tão inflamável, através da exibição de um pequeno vídeo sobre o 
acidente do dirigível Hindenburg, ocorrido em maio de 1937 e outro vídeo sobre a utilização do gás hidrogênio como combustível.

O gás hidrogênio se apresenta como uma fonte alternativa de energia basicamente em função de duas características bastante distintas dos demais combustíveis (especialmente os de origem fóssil): elevada entalpia de combustão (seu poder calorífico é cerca de 2,5 vezes maior que o da gasolina) e sua queima produz apenas água (enquanto outros combustíveis liberam óxidos de enxofre e de carbono, que contribuem tanto para o aquecimento global quanto para a ocorrência de chuvas ácidas). Entretanto, a utilização do gás hidrogênio em larga escala ainda é limitada em função de fatores como: indisponibilidade de hidrogênio livre na natureza, dificuldade de armazenagem e alta inflamabilidade (PORCIÚNCULA, 2013).

Mais uma vez, o professor, enquanto mediador, suscitou o questionamento sobre as possíveis formas de se produzir gás hidrogênio. Neste caso, foi permitido aos alunos que expusessem seu conhecimento sobre o tema ou mesmo divagassem sobre formas hipotéticas de produção do gás.

Apesar da sugestão de alguns sobre a produção através de outras formas, em função de limitações materiais, optou-se pela produção do gás hidrogênio in situ, a partir da reação entre alumínio metálico e água em presença de soda cáustica, sendo observadas todas as medidas de segurança. Tal reação, quando comparada a outras reações entre metas e água, tem a vantagem de produzir o gás hidrogênio de forma mais controlada, o que não exime o professor de tomar todas as precauções posto que a reação é extremamente exotérmica (SANTOS e SILVA, 2015).

Em função da opção pelo questionário semiestruturado, foi observado um aspecto a ser considerado resultado na pesquisa: os participantes demonstraram ter conhecimento total, parcial ou nulo acerca dos temas relacionados à atividade. Todas as respostas foram analisadas e categorizadas pela comparação com gabarito predefinido.

Para tanto, foi redigida uma resposta para cada questão contendo determinado conjunto de palavras-chave (BARDIN, 2011). Considerou-se que o 
sujeito demonstrou ter total conhecimento do tema (de cada questão) quando ele, em sua resposta, citou, ao menos, um (ou mais) termo(s) corretamente associado(s) ao gabarito, sem, no entanto, escrever algo que contradissesse o mesmo. Consideramos que o sujeito demonstrou ter parcial conhecimento do tema quando ele, apesar de ter escrito, pelo menos, uma palavra contida no gabarito, contradisse o sentido do mesmo. Finalmente, o sujeito foi categorizado como tendo conhecimento nulo do tema quando não utilizou sequer uma das palavras-chave ou simplesmente não respondeu a questão.

\section{RESULTADOS E DISCUSSÃO}

A análise dos questionários respondidos por pais / responsáveis permitiu caracterizar o indivíduo que participou da pesquisa. Considerando todos os participantes $(n=17)$ do evento no qual a atividade pedagógica foi aplicada, foi possível caracterizar um indivíduo com idade média de 11,5 anos, aluno do Ensino Fundamental I (53\%) da rede privada (76\%), identificado com altas habilidades ou superdotação através de algum teste psicométrico (59\%) e que nunca foi reprovado na escola (94\%). Parte desses alunos foi acelerada na escola (53\%), não apresenta dupla excepcionalidade (88\%) e tem interesse pelas Ciências Naturais (82\%), mas nunca participou de atividade extracurricular dessa natureza $(71 \%)$.

A análise destes resultados permite algumas considerações acerca da representação do indivíduo com altas habilidades ou superdotação. Por exemplo, quanto ao tipo de escola, o fato de haver na pesquisa um número maior de alunos oriundos de escola privada ratifica a dificuldade de avaliar e identificar alunos com altas habilidades ou superdotação com baixa representação cultural e linguística e de contextos socioeconômicos desfavorecidos (FRIEDMAN-NIMZ E SKYBA, 2009).

A diversidade de características de um indivíduo superdotado constitui um obstáculo ao processo de identificação, entretanto as ideias errôneas acerca do tema interferem e dificultam uma educação que promova um melhor desenvolvimento do aluno com altas habilidades ou superdotação (ALENCAR, 2007). 
Nesse sentido, diversos são os trabalhos (RECH e FREITAS, 2005; ANTIPOFF e CAMPOS, 2010) que ratificam a existências de "mitos" relacionados à superdotação. Os mitos constituem uma "representação coletiva muito simplista e muito estereotipada, comum a um grupo de indivíduos" (RUSS, 1994); surgem como forma de compreender determinada realidade estranha à sociedade, tendo forte componente histórica e social. Normalmente, compreendem uma visão "précientífica" sobre um tema ou fenômeno, não resistindo a uma análise mais profunda. Ainda assim, permanecem no imaginário coletivo interferindo sobremaneira no atendimento ao superdotado.

Nesse sentido, os mitos podem estar tanto relacionados às características ou ao comportamento quanto ao próprio conceito. No que tange a caracterização, observa-se frequentemente a ideia errônea de que o indivíduo com altas habilidades ou superdotação tem elevado quociente de inteligência ou apresenta destaque em todas as áreas do currículo escolar (ANTIPOFF e CAMPOS, 2010). Estas ideias não levam em conta o fato de que testes de inteligência nem sempre são suficientes para identificar o tipo de superdotação definida por Renzulli (1998) como criativoprodutiva ou mesmo o conceito de inteligências múltiplas proposto por Gardner (2000).

Esbarra-se também no mito de que o indivíduo com altas habilidades ou superdotação será um adulto eminente (WINNER, 1998). Nesse caso, o indivíduo sente-se pressionado a obter excelentes resultados acadêmicos, entretanto, por condições intrínsecas (como motivação ou personalidade) ou extrínsecas (como práticas educacionais inadequadas), os resultados não atendem às expectativas gerando nos pais, professores e, sobretudo, no indivíduo um profundo sentimento de frustração. Considerando-se o público-alvo da pesquisa, percebe-se a contraposição entre estes mitos e o fato de haver um aluno com histórico de reprovação escolar entre os indivíduos com altas habilidades ou superdotação.

Outra questão a ser discutida na análise do perfil dos participantes é a existência de alunos com dupla excepcionalidade. $O$ indivíduo nessa condição é aquele que apresenta o comportamento de superdotação associado à desordem psiquiátrica, educacional, sensorial e física. Essa condição se contrapõe ao mito de 
que pessoas com altas habilidades não podem apresentar ao mesmo tempo deficiências ou condições incompatíveis com essas características (NAKANO e SIQUEIRA, 2012; PFEIFFER, 2013; ALVES e NAKANO, 2015).

Quanto à análise dos questionários semiestruturados, a observação constitui um dos principais instrumentos de coleta de dados em abordagens qualitativas permitindo ao observador a aproximação da perspectiva dos sujeitos, entretanto atribui-se à técnica provocar, por vezes, alterações no ambiente ou no comportamento da população estudada. Tal relação, normalmente questionada por pesquisadores de orientação positivista, nesse caso, é inerente ao processo de investigação (ALVES, 1991).No presente trabalho, a análise qualitativa foi feita a partir de organização por categorias segundo a ocorrência de determinadas palavras ou conceitos (BARDIN, 2011).

O quadro 1 apresenta, em termos percentuais, o quantitativo de participantes que demostraram ter conhecimento total, parcial ou nulo sobre a necessidade da presença de gás oxigênio em uma reação de combustão bem como a produção de gás carbônico nesse tipo de reação (um dos poluentes atmosféricos responsáveis pelo agravamento do efeito estufa).

Quadro 1: Respostas dos testes dos sujeitos da pesquisa no segundo evento $(n=17)$.

\begin{tabular}{|l|c|c|c|c|c|c|}
\hline \multirow{2}{*}{ Questão } & \multicolumn{3}{|c|}{ Pré-teste } & \multicolumn{3}{c|}{ Pós-teste } \\
\cline { 2 - 7 } & Total & Parcial & Nulo & Total & Parcial & Nulo \\
\hline $\begin{array}{l}\text { 1. Por que a vela apaga quando a colocamos } \\
\text { dentro do recipiente fechado? }\end{array}$ & $70 \%$ & $26 \%$ & $4 \%$ & $87 \%$ & $13 \%$ & $0 \%$ \\
\hline 2. Qual(is) produto(s) da reação de combustão? & $13 \%$ & $35 \%$ & $52 \%$ & $35 \%$ & $35 \%$ & $30 \%$ \\
\hline $\begin{array}{l}\text { 3. Você sabe informar um tipo de combustão } \\
\text { cujos produtos não geram impactos ambientais? }\end{array}$ & $0 \%$ & $17 \%$ & $83 \%$ & $22 \%$ & $17 \%$ & $61 \%$ \\
\hline
\end{tabular}

Fonte: Elaborado pelos autores (2016)

Como parâmetro de comparação, foi tomado como exemplo a questão 1, cuja resposta-padrão deveria ter os seguintes termos: oxigênio / comburente - término / falta. Comparando as respostas do aluno 1 no pré-teste e no pós-teste foi observada uma mudança conceitual significativa:

Aluno 1 (pré-teste): Por que o oxigênio sai. 
Aluno 1 (pós-teste): Por que o oxigênio vai acabando de pouco em pouco.

Segundo a análise, no pré-teste, o aluno 1 demonstrou ter um conhecimento parcial do tema pois, apesar de ter utilizado corretamente o termo "oxigênio" em referência ao reagente limitante no processo, demonstrou confusão entre o conceito de consumo do reagente ao longo do processo com a ideia de falta desse gás em função sua saída.

Durante décadas, professores de Ciências ou de Química, acreditaram, de forma equivocada, ser possível determinar o teor de oxigênio contido no ar atmosférico através da queima de uma vela contida em um recipiente fechado (BRAATHEN, 2000). Tal experimento, a despeito de sua simplicidade, pode revelar confusões conceituais mesmo entre professores. Specht e colaboradores (2015) apontam para o fato de que $64 \%$ dos professores da Educação Básica, sujeitos de sua pesquisa, elaboraram perguntas sobre o experimento com falhas conceituais decorrentes da confusão entre senso comum e conhecimento científico. Logo, podese considerar razoável que uma criança / adolescente ofereça também uma resposta conceitualmente incorreta.

Quanto à questão 2, foi adotado como padrão de resposta os termos gás carbônico - água - calor / energia. A análise das respostas do aluno 2, em cada teste permite-nos avaliar diversos aspectos do seu discurso.

Aluno 2 (pré-teste): Calor, energia e gás carbônico.

Aluno2 (pós-teste): Água, $\mathrm{CO}_{2}$ e $\mathrm{N}_{2} \mathrm{O}$.

Apesar de demonstrar que ainda não compreende calor como manifestação de energia, o aluno 2 demonstrou ter, já no pré-teste, total conhecimento do tema (a despeito de não ter citado a água). No pós-teste, ele, além de citar a água em sua resposta, escreveu as fórmulas químicas de substâncias (gás carbônico e óxido nitroso) e, apesar do óxido nitroso não ser propriamente um dos produtos da reação, ele o citou, provavelmente, por ter sido dito que, de fato, a queima de combustíveis fósseis gera também óxidos de enxofre e nitrogênio que contribuem para o agravamento do fenômeno chuva ácida.

Neste aspecto, a atividade experimental, consideração a mediação do professor, pode tanto promover a mudança conceitual como a apropriação de novos 
conceitos. Considera-se nessa perspectiva, o conceito de zona de desenvolvimento proximal proposto por Vygotsky (2000) entendida como o espaço no qual, graças à interação e à colaboração de outros mais capazes, uma determinada pessoa pode realizar uma tarefa de maneira e em nível que não seria capaz de alcançar individualmente. Tal proposição é ratificada por Freire (1987) que recorre aos especialistas na definição dos conhecimentos científicos de cada área, indispensáveis para a compreensão de um tema em questão. Nesse sentido, os temas norteiam a seleção dos conhecimentos a serem trabalhados e os especialistas definem o conhecimento científico como um aporte, algo novo a ser apropriado no contexto dos temas (GEHLEN et al, 2008). Essa mudança conceitual corrobora para a desconstrução do mito de que o indivíduo com altas habilidades ou superdotação é um autodidata, não necessitando, pois, de atendimento (WINNER, 1998).

Ainda sobre a questão 2, o aluno 3 demonstrou ter confundido os conceitos de reagente e produto no pré-teste, entretanto percebemos a mudança conceitual em função da resposta no pós-teste.

Aluno 3 (pré-teste): Um combustível.

Aluno 3 (pós-teste): Água, gás carbônico.

Tal confusão é ratificada pelas respostas do mesmo aluno à questão 3.

Aluno 3 (pré-teste): Água.

Aluno 3 (pós-teste): Sim, o hidrogênio.

Segundo os Parâmetros Curriculares Nacionais (PCN), os conceitos de reagente, produto e, sobretudo, reação química são considerados centrais no ensino de Química (BRASIL, 1999). Contudo, diversos autores reconhecem a dificuldade para o ensino e a aprendizagem destes temas, em face na necessidade do domínio de conhecimentos prévios e da articulação entre mudanças ao nível macroscópico e microscópico (MENDES, 2011).

O aluno 4, por exemplo, do nono ano do Ensino Fundamental, demonstrou ter superado uma confusão conceitual em relação ao tipo de combustão que não geraria impactos ambientais (questão 3):

Aluno 4 (pré-teste): A combustão elétrica. 
Aluno 4 (pós-teste): Hidrogênio.

Já o aluno 5, do quarto ano do Ensino Fundamental, para a mesma questão, ofereceu as seguintes respostas:

Aluno 5 (pré-teste): ?

Aluno 5 (pós-teste): $H$ [sic].

Nestes casos, os dois alunos, de idades tão díspares, demonstraram, ao final do experimento, ter alcançado o mesmo patamar em relação ao conhecimento. Esta observação ajuda a refutar o mito de que indivíduos tão jovens não devem ser expostos a temas considerados mais complexos em função da pouca idade. Vale ainda ressaltar que o aluno 5 se apropriou inclusive da representação simbólica do elemento hidrogênio (ainda que, em termos conceituais, a representação correta a ser utilizada neste caso fosse $\mathrm{H}_{2}$ ).

Outro aspecto a ser ressaltado, é a reelaboração das respostas ao compararmos os pré-testes e pós-testes. Enquanto o aluno 6 oferece uma resposta coerente, porém mais simples, para a questão 1 , no pré-teste, esse mesmo aluno reelabora sua resposta tornando-a mais complexa e acrescenta um desenho a fim de demonstrar o que está afirmando.

Aluno 6 (pré-teste): Apagarão em tempos diferentes, começando com a mais alta e descendo, porque a mais alta tem menos acesso ao oxigênio no recipiente.

Aluno 6 (pós-teste): Não, a de cima apagará primeiro por que [sic] gás carbônico é mais leve do que o oxigênio e sobe - então, o oxigênio fica embaixo do gás. É o mesmo efeito num incêndio e no efeito estufa.

A comparação entre as duas respostas corrobora a hipótese proposta por Ausubel (1963, 1968 apud GUIMARÃES, 2009) de que, para que haja aprendizagem significativa, há a necessidade de subsunçores que estabelecerão ligações entre o que se sabe e o que se está aprendendo. Assim, uma nova informação ancora-se a conceitos relevantes preexistentes na estrutura cognitiva do aprendiz, emprestandoIhes significado.

A primeira hipótese corrobora a ideia de Duan e colaboradores (2009) e Liu e colaboradores (2011) que propõem que indivíduos superdotados precisam ser desafiados sempre com atividades que exijam mais atenção, o que permite a eles 
exercitarem seu potencial. A segunda hipótese reforça a proposição de Tacca (2006 apud CAVALHEIRO e FERNANDES, 2016) o desafio no ensino é encontrar as estratégias que permitam ao aluno operar reflexivamente na direção da apropriação do conhecimento. Para tanto, o professor precisa organizar e coordenar seu conhecimento sobre a criança, sobre si próprio e sobre o conhecimento a ser construído.

Outro aspecto relevante a ser considerado na aplicação da atividade é número de respostas "em branco" no pré-teste e no pós-teste. O quadro 2 apresenta o número de questões não respondidas antes e depois da realização de toda a atividade.

Quadro 2: Número de respostas em branco de acordo com a questão ( $n=17)$.

\begin{tabular}{|c|c|c|}
\hline \multirow{2}{*}{ Questão } & \multicolumn{2}{|c|}{ Resposta em branco } \\
\cline { 2 - 3 } & Pré-teste & Pós-teste \\
\hline 1 & $0 \%$ & $0 \%$ \\
\hline 2 & $9 \%$ & $9 \%$ \\
\hline 3 & $78 \%$ & $43 \%$ \\
\hline
\end{tabular}

Fonte: Elaborado pelos autores (2016).

O experimento da vela em um recipiente fechado, além de bastante simples, é bastante difundido no ambiente escolar (BRAATHEN, 2000). Ainda que a proposta tivesse transcendido o experimento clássico, considerando a familiaridade deste experimento e o conteúdo da questão 1, pode-se compreender o fato de nenhuma criança / adolescente ter deixado de responder tal questão. Além disso, a questão pede uma explicação que pode ser construída de diferentes formas.

As questões 2 e 3, no entanto, exigem respostas específicas. Ademais, podese atribuir às questões 2 e 3, respectivamente, um aumento progressivo no nível de conhecimento exigido. Este aumento justifica o aumento no número de alunos que não responderam coisa alguma nas questões seguintes.

Esta observação ratifica a proposição de que o superdotado, quando submetido a situações desconhecidas, dificilmente se expõe a ponto de simplesmente "chutar" uma resposta. Este aspecto vai ao encontro de alguns mitos 
relacionados ao superdotado como o fato de serem bons em todas as áreas de conhecimento e de não precisarem de apoio para realizarem as suas tarefas (EXTREMIANA, 2000).

\section{CONCLUSÕES}

Os indivíduos com indicadores de altas habilidades ou superdotação são aqueles que possuem ou são capazes de desenvolver um conjunto de traços humanos e aplicá-los a qualquer área potencialmente valiosa do desempenho humano. O professor ocupa uma posição privilegiada tanto na identificação quanto no atendimento ao indivíduo superdotado, pois, ao oferecer atividades que estimulem a curiosidade e a criatividade, pode, tanto perceber as potencialidades do aluno, quanto suplementar seu currículo.

Assim como a experimentação ocupa um lugar privilegiado numa metodologia científica, pode ocupar um lugar importante no processo de aprendizagem. Se, por um lado, a experiência exigente conduz a desestabilização, a quebra de previsibilidade e a reflexão crítica, por outro, a atividade experimental, à luz da pedagogia problematizadora, suscita o espírito crítico, a curiosidade e a não aceitação do conhecimento simplesmente transferido.

Considerando o perfil de criança / adolescente participante da pesquisa, foi possível ratificar proposições como a dificuldade de avaliar e identificar alunos com altas habilidades ou superdotação com baixa representação cultural e linguística e de contextos socioeconômicos desfavorecidos. No entanto, foi possível criticar mitos como o de que indivíduos com altas habilidades têm apresenta destaque em todas as áreas do currículo escolar e o de que pessoas com altas habilidades não podem apresentar ao mesmo tempo deficiências ou condições incompatíveis com essas características.

Quanto à análise dos questionários semiestruturados, a diversidade de dados obtidos na análise dos resultados dos testes aplicados no evento permitiu observar tanto uma mudança conceitual nos participantes quanto outros aspectos subliminares observados como características de sujeitos com altas habilidades ou 
superdotação, indicando inclusive que uma pesquisa orientada auxilia no desenvolvimento de conceitos e atitudes. A transcrição de algumas respostas dos questionários ratifica a proposição de que a atividade experimental mediada pelo professor pode tanto promover a mudança conceitual como a apropriação de novos conceitos. Tal mudança corrobora para a desconstrução do mito de que o indivíduo superdotado não necessita de atendimento.

A análise das respostas de todas as questões permite afirmar que o percentual de participantes que, ao final da atividade, demonstrou ter um conhecimento total sobre o assunto referente ao tema aumentou, bem como diminuiu o número de participantes que demonstrou ter conhecimento nulo.

Quanto ao oferecimento da atividade experimental, conclui-se que houve a adesão dos superdotados às atividades bem como o interesse em participar de atividades semelhantes se estas Ihes fossem oferecidas, o que ratifica a proposição de que indivíduos superdotados têm interesse por espaços de trocas de experiências entre pares.

\section{REFERÊNCIAS}

ALENCAR, Eunice M. L. S. Características sócio-emocionais do superdotado: questões atuais. Psicologia em estudo, Maringá, v. 12, n. 2, p. 371-378, Mai./Ago. 2007.

ALENCAR, Eunice M. L. S; FLEITH, Denise S. Superdotados: determinantes, educação e ajustamento. 2. ed. São Paulo: EPU, 2001. 188 p.

ALVES, Alda J. O planejamento de pesquisas qualitativas em educação. Cad. Pesq., São Paulo. n. 77, p. 53-61, Mai. 1991.

ALVES, Rauni J. R.; NAKANO, Tatiana C. A dupla-excepcionalidade: relações entre altas habilidades/superdotação com a Síndrome de Asperger, transtorno de déficit de atenção e hiperatividade e transtornos de aprendizagem. Revista Psicopedagogia, Campinas, v. 32, n. 99, p. 346-360, 2015a.

ANTIPOFF, Cecília A.; CAMPOS, Regina H. F. Superdotação e seus mitos. Rev. Psico. Escolar e Educacional, v. 14, n. 2, p. 301-309, 2010.

BACHELARD, Gaston. Formação do espírito científico. Rio de Janeiro: Contraponto, 1996. 314 p.

BARDIN, Laurence. Análise de Conteúdo. São Paulo: Edições 70, 2011. 278 p. 
BRAATHEN, Per C. Desfazendo o mito da combustão da vela para medir o oxigênio do ar. Química Nova na Escola, São Paulo, n. 12, p. 43-45, Nov. 2000.

BRASIL. Conselho Nacional de Educação. Câmara de Educação Básica. Resolução CNE/ CEB $n^{\circ}$ 2/2001, de 11 de setembro de 2001. Diário Oficial da União, Brasília, DF, 14 set. 2001. Seção 1E, p. 39-40.

BRASIL. Conselho Nacional de Educação. Câmara de Educação Básica. Resolução CNE/ CEB $n^{\circ}$ 4, de 2 de outubro de 2009. Diário Oficial da União, Brasília, DF, 5 out. 2009. Seção 1, p. 17.

BRASIL. Conselho Nacional de Saúde. Resolução CNS n. 510, de 07 de abril. Brasília, 2016.

BRASIL. Ministério da Educação. Secretaria de Educação Especial. Política Nacional de Educação Especial na perspectiva da Educação Inclusiva. Brasília, DF: MEC/SEESP, 2008.

BRASIL. Ministério da Educação e Cultura. Secretaria de Educação Média e Tecnológica. Parâmetros Curriculares Nacionais: Ensino Médio. Brasília, DF: MEC/SENTEC, 1999.

BRASIL. Presidência da República. Casa Civil. Subchefia para assuntos jurídicos. Lei de Diretrizes e Bases da Educação Nacional. Lei no 9394, de 20 de dezembro. Brasília, 1996.

Diário Oficial da União, Brasília, DF, 23 dez. 1996. Seção 1, p. 27833.

CARDOSO, Fernanda S. Rede de Interações como possibilidade para o desenvolvimento de pessoas com altas habilidades e vocações na área de biotecnologia. Doutorado em Ciências e Biotecnologia - Programa de Pós-Graduação em Ciências e Biotecnologia, Universidade Federal Fluminense, Niterói, 2016. 271p.

CAVALHEIRO, Juliana M.; FERNANDES, Vera L. P. O ensino de artes visuais para alunos com altas habilidades e superdotação. Florianópolis, Educação, Artes e Inclusão. v. 12, n. 2, p 49-72, 2016.

CONDURÚ, Marise T.; PEREIRA, José A. R. Elaboração de Trabalhos Acadêmicos: Normas, Critérios e Procedimentos. 4a edição. Pará: EDUFPA, 2010.

DELIZOICOV, Demétrio. Problemas e Problematizações. In: Pietrocola, M. (Org.). Ensino de Física: Conteúdo, Metodologia e Epistemologia em uma Concepção Integradora. Florianópolis: UFSC, p. 1-13, 2005.

DELOU, Cristina M. C. Sucesso e fracasso escolar de alunos considerados superdotados: um estudo sobre a trajetória escolar de alunos que receberam atendimento em salas de recursos de escolas da rede pública de ensino. Tese (Doutorado em Educação). Faculdade de Educação. Pontifícia Universidade Católica de São Paulo. 2001. 240 p.

DUAN, Xiaoju; SHI, Jiannong; WU, Jianhui; MOU, Yi; CUI, Hairong; WANG, Guiqing. Eletrophysiological correlates for responseinhibition in intellectually gifted children: $\mathrm{A} G \mathrm{Go}$ NoGo study. NeuroscienteLetters,v. 457, p. 45-48, 2009.

EXTREMIANA, Amparo A. Niños Superdotados. Madrid: Pirámide, 2000. 275 p.

FRANCISCO JR, Wilmo E.; FERREIRA, Luiz H.; HARTWIG, Dácio R. Experimentação problematizadora: fundamentos teóricos e práticos para a aplicação em salas de aula de ciências. Química Nova na Escola, São Paulo, n. 30, p. 34-41, Nov. 2008. 
FRANCISCO JR., Wilmo E. Uma abordagem problematizadora para o ensino de interações intermoleculares e conceitos afins. Química Nova na Escola, São Paulo, n. 29, p. 20-23, Ago. 2008.

FREIRE, P. Pedagogia do oprimido. 43ª ed. Rio de Janeiro: Paz e Terra, 2005.

FREIRE, P. Pedagogia da autonomia: saberes necessários à prática educativa. $33^{\mathrm{a}}$ ed. Rio de Janeiro: Paz e Terra, 2006.

FRIEDMAN-NIMZ, Reva; SKYBA, Olha. Personality qualities that help or hinder gifted and talented individuals. In: International handbook on giftedness. Springer: Netherlands, $p$. 421-435, 2009.

GARDNER. Howard. Inteligência: um conceito reformulado. Rio de Janeiro: Objetiva, 2000. $347 \mathrm{p}$.

GEHLEN, Simoni T.; AUTH, Milton A.; AULER, Décio; PANSERA-DE-ARAÚJO, Maria C.;

MALDANER, Otávio A. Freire e Vigotski no contexto da Educação em Ciências: aproximações e distanciamentos. Ens. Pesqui. Educ. Ciênc., Belo Horizonte. v. 10, n. 2, p. 279-298, 2008.

GIL, António C. Métodos e Técnicas de Pesquisa Social. 6a edição. São Paulo: Atlas, 2008. 200 p.

GIORDAN, Marcelo. O papel da experimentação no ensino de ciências.Química Nova na Escola, São Paulo, v. 10, p. 43-49, 1999.

GUIMARÃES, Cleidson C. Experimentação no ensino de Química: caminhos e descaminhos rumo à aprendizagem significativa. Química Nova na Escola, São Paulo, v. 31, n. 3, p. 198-202, Ago. 2009.

LIU, T, XIAO, T; SHI, J; ZHAO, D. Response preparation and cognitive control of highly intelligent children: a Go-NoGo event - related potential. Neuroscience, v. 180, p. 122-128, 2011.

MENDES, Maricleide P.L. O conceito de reação química no nível médio: história, transposição didática e ensino. Dissertação (Mestrado em Ensino, Filosofia e História das Ciências). Universidade Federal da Bahia. Julho de 2011. 213 p.

MORTIMER, Eduardo F. Pressupostos epistemológicos para uma metodologia de ensino de química: mudança conceitual e perfil epistemológico. Química Nova, São Paulo, v. 15, n. 3, p. 242-249, 1992.

NAKANO, Tatiana C.; SIQUEIRA, Luciana G. G. Revisão de publicações periódicas brasileiras sobre superdotação. Revista Educação Especial, Santa Maria, v. 25, n. 43, p. 249-66, 2012.

OLIVEIRA, Ema Patrícia L. Alunos sobredotados: a aceleração escolar como resposta educativa. Tese (Doutorado em Psicologia). Instituto de Educação e Psicologia. Universidade do Minho. Junho de 2007. 278 p.

PATTO, Maria Helena S. Para uma crítica da razão psicométrica. Psicologia USP, São Paulo, v. 8, n. 1, p. 47-62. 1997. 
PFEIFFER, Steven I. Gifted students with a coexisting disability: the twice exceptional. Estudos de Psicologia, Campinas, v. 32, n. 4, p. 717-727, Dez. 2015.

PORCIÚNCULA, Cleitom B. Simulação e operação de célula de combustível com geração in situ de hidrogênio através da corrosão alcalina do alumínio. Tese (Doutoramento em Engenharia Química). Escola de Engenharia. Universidade Federal do Rio Grande do Sul. 2013. 202 p.

RECH, Andréia J. D.; FREITAS, Soraia N. Uma análise dos mitos que envolvem os alunos com altas habilidades: a realidade de uma escola de Santa Maria/RS.Rev. Bras. Ed. Esp., Marília, v. 11, n. 2, p. 295-314, Mai./Ago. 2005.

RENZULLI, Joseph S. O que é esta coisa chamada superdotação e como a desenvolvemos? Retrospectiva de vinte e cinco anos. Revista Educação, Porto Alegre, ano 27, n. 1, jan./abr. 2004.

RUSS, Jacqueline. Dicionário de Filosofia. São Paulo: Scipione, 1994. 382 p.

SANTA CATARINA (Estado). Secretaria de Estado da Educação. Fundação Catarinense de Educação Especial. Altas habilidades/superdotação rompendo as barreiras do anonimato. Andréia Rosélia Alves Panchiniack (coord). São José: FCEE, 2011. 40 p.

SANTOS, Danilo O.; SILVA, Gisleine. S. Produção de hidrogênio a partir de materiais alternativos por alunos do Ensino Médio. Scientia Plena, Aracaju, v. 11, n. 6. 2015.

SÃO PAULO (Estado). Secretaria de Educação. Centro de Apoio Pedagógico Especializado. Um olhar para as altas habilidades: construindo caminhos. Christina Menna Barreto Cupertino (org). São Paulo: FDE, 2008. 87 p.

SCHNETZLER, Roseli P. e ARAGÃO, Rosália M. R. Importância, sentido e contribuições de pesquisas para o ensino de química. Química Nova na Escola, São Paulo, v. 1, p. 27-31. 1995.

SPECHT, Cristiano C.; RIBEIRO, Marcus E. M.; RAMOS, Maurivan G. A importância da pergunta dos aprendentes no ensino e na aprendizagem em Ciências. Trabalho apresentado no X Encontro Nacional de Pesquisa em Educação em Ciências (X ENPEC), Águas de Lindóia, 2015.

VIGOTSKI, Lev S. A Construção do Pensamento e da Linguagem. 1 ed. Trad. Paulo Bezerra. São Paulo: Martins Fontes, 2000. 496 p.

WINNER, Ellen. Crianças superdotadas: Mitos e realidades. Porto Alegre: Artmed, 1998. $289 \mathrm{p}$. 